\title{
Nutritional value of cooked offal derived from free-range rams reared in South Africa
}

\author{
L.C. Hoffman, L.L. Laubscher, K. Leisegang
}

\begin{abstract}
Nutritional value of Dorper $(n=10)$ and Merino $(n=10)$ by-products were evaluated. Proximate composition differed between organs and breeds with Merino heart $(68.9 \mathrm{~g} / 100 \mathrm{~g})$, spleen $(77.2 \mathrm{~g} / 100 \mathrm{~g})$ and testicles $(83.7 \mathrm{~g} / 100 \mathrm{~g})$ having higher moisture contents than their Dorper counterparts. Dorper brain (10.1 g/100 g), heart $(15.2 \mathrm{~g} / 100 \mathrm{~g})$, spleen $(20.4 \mathrm{~g} / 100 \mathrm{~g})$ and testicles $(12.9 \mathrm{~g} / 100 \mathrm{~g})$ had higher protein contents than Merino. Dorper organs also tended to have a lower fat content. Amino acid and fatty acid profiles differed between organs and breeds. Few differences were noted in total SFA and MUFA. Dorper heart (1.8\%) had significantly lower total PUFA than Merino heart (7.3\%). All the organs showed favourable P:S ratios, with the exception of the tongue, heart and stomach. Dorper and Merino brain, lungs and testicles had favourable $n-6 / n-3$ ratios. Cholesterol content differed between both organs and breeds. The value of offal as food is discussed further.
\end{abstract}

\section{Introduction}

The so-called fifth quarter of a carcass is traditionally consumed in a number of countries and its general consumption around the world is escalating. Organs recovered from slaughtered animals offer a range of foods which are nutritionally attractive (U S Department of Agriculture \& Agricultural Research Service, 2011). Edible organs are highly prized in South East Asia and Africa, whilst demand is variable and low in Australia and USA, respectively (Fatma and Mahdey, 2010 and Pearson and Dutson, 1988). In some African countries, edible offal contributes $33 \%$ more edible material per animal slaughtered and reduces the whole carcass price by 42.3\% (Aduku, Aganga, Okoh, Ingawa, \& Phillip, 1991). In South Africa, when visiting abattoirs, managers and owners are quick to point out that the value of the offal (organ meat) is on the increase. Offal was traditionally sold to the lower income market; however, with the increase in tourism, some of the offal products are becoming delicacies in niche markets, particularly in restaurants. In the Encyclopaedia of Meat Sciences, Ockerman and Basu (2004) give a good synopsis of some of the products that can be made from various organs/variety meats. Irrespective of who the end consumer is, there is a need in the industry for more information on the nutritional value of the major offal found in livestock. Scientific literature on the nutritional value of offal is relatively scarce with limited data available on the internet in the form of nutritional food tables - the USDA Nutrient database does contain some nutritional information under the caption of "variety meat and by-products" (U S Department of Agriculture \& Agricultural Research Service, 2011). These, however, are generally species specific with few focusing on nutritional composition differences as a result of other extrinsic and intrinsic factors. Authors such as Park, Kouassi, and Chin (1991) have, however, reported slight differences between goat breeds for the moisture, total fat and cholesterol content of the liver, kidney and heart. In a later study, Park and Washington (1993) reported significant differences in the fatty acid composition of organ meat between two goat breeds and between organs within the breeds. On the other hand, 
Kamalzadeh, Koops, van Bruchem, Tamminga, and Zwart (1998) noted that diet restriction had little influence on the early maturing organs as they had a priority for available nutrients over the later developing organs/body parts.

Furthermore, research findings reported in the public domain often only include selected chemical analyses of a few organs, for example proximate composition, cholesterol content and fatty acid profiles of the brain, heart, liver and tongue (Abdullah, 2008, Kiernat et al., 1964, Mustafa, 1988, Schweigert et al., 1953 and Williams, 2007). In South Africa, specifically, where offal consumption is generally higher than in many other countries, limited if any data is available on the nutritional composition of this offal. In the present investigation, the aim is to determine the nutritional value of the major offal from Dorper and Merino type lambs from the same region reared in a free range (natural pasture) system since both breeds are particularly popular in the South African agricultural industry. The Dorper is an early maturing breed relative to the Merino, that was selected for its hardiness and is a composite breed derived in South Africa from a cross between the Dorset Horn and the Blackheaded Persian (Milne, 2000).

\section{Materials and methods}

\subsection{Animals and organs}

Twenty animals, ten Dorper sheep and ten Merino sheep, reared in a free-range extensive system in South Africa, where they only consumed natural grazing and slaughtered using standard South African techniques at LAW abattoir (Upington, South Africa) were randomly selected from the day's slaughter $(n=1000)$. Although age and production region may have had an effect on the chemical composition, it was decided to select sheep from the two major breeds reared in South Africa from the same region (Karoo) and also from the most common age class slaughtered. Therefore, the sheep sampled were all A2 or A3 carcass classes (indicating them to be lambs with no permanent molar teeth and having a fat depth of 1-7 $\mathrm{mm}$ measured $25 \mathrm{~mm}$ from the midline between the $3 \mathrm{rd}$ and 4 th lumbar vertebrae; an A3 lamb being the fatter). Nine organs were removed immediately after slaughter from each of the animals, including the brain, tongue, stomach, liver, heart, lungs, spleen, kidneys and testicles. The experimental design was thus a 2 (breeds: Dorper and Merino) $\times 10$ (animals: rams) $\times 9$ (organs: brain, tongue, stomach, liver, heart, lungs, spleen, kidneys and testicles) design.

Each of the organs was individually labelled, frozen and transported to the Stellenbosch University meat laboratory for further analyses. At the laboratory, the samples were defrosted and cooked inside a plastic bag within a water bath set at $60{ }^{\circ} \mathrm{C}$ for 60 min. Cooked samples were homogenized together with the cooking losses (juices) in a bowl with suitable blade until they were paste-like. Samples were then vacuum sealed and stored at $-20{ }^{\circ} \mathrm{C}$ until analyses could be performed.

\subsection{Chemical analyses}

\subsubsection{Proximate composition}

The moisture contents (g/100 g organ meat) of all the cooked samples were determined according to the Association of Official Analytical Chemist's Standard Methods (AOAC, 1997). The moisture content was determined by drying a $2-\mathrm{g}$ sample at $100-105{ }^{\circ} \mathrm{C}$ for $24 \mathrm{~h}$ (AOAC Official method 934.01). After drying samples were weighed and ashed at $500{ }^{\circ} \mathrm{C}$ for $6 \mathrm{~h}$ to determine ash content (AOAC Official method 942.05). 
The fat content was determined by homogenizing the samples in a blender, followed by chloroform:methanol (2:1) extraction (Lee, Trevino, \& Chaiyawat, 1996). To determine the protein content, the sample residue from the fat analysis was dried (as per moisture determination) and ground with a pestle in a mortar to a fine powder. Samples of $0.150 \mathrm{~g}$ were inserted into a foil wrap designed for the Leco protein analyzer (LECO FP-528 Protein/Nitrogen Detector, LECO Corporation, St. Joseph, USA). The nitrogen content was multiplied by 6.25 to calculate the protein concentration in the sample. An EDTA calibration sample (LECO Corporation, USA, Part number 502-092) was analysed with each batch of samples to ensure accuracy and recovery rate.

The accuracy and repeatability of all the techniques used above were controlled on a bimonthly basis by means of a National Inter-laboratory scheme (AgriLASA: Agricultural Laboratory Association of South Africa) wherein blind samples are analysed.

\subsubsection{Fatty acid profile and cholesterol content}

After thawing, a 2-g cooked sample was extracted with a chloroform:methanol (2:1; v/v) solution according to the method of Folch, Lees, and Sloane Stanley (1957). All the extraction solvents contained $0.01 \%$ butylated hydroxytoluene (BHT) as antioxidant. A polytron mixer (WiggenHauser Homogenizer, Berlin, Germany, D-500 fitted with a standard shaft 1; speed setting D) was used to homogenize the sample with the extraction solvent. Heptadecanoic acid (C17:0) was used as an internal standard (catalogue number H3500, Sigma-Aldrich Inc., St. Louis, USA) to quantify the individual fatty acids. Of the extracted lipids, $250 \mu \mathrm{l}$ was transmethylated for $2 \mathrm{~h}$ at $70{ }^{\circ} \mathrm{C}$ with $2 \mathrm{ml}$ of a methanol/sulphuric acid (19:1; v/v) solution as transmethylating agent. After cooling to room temperature, the resulting fatty acid methyl esters (FAMEs) were extracted with water and hexane. The top hexane phase was transferred to a spotting tube and dried under nitrogen. Fifty microliters of hexane was added to the dried sample of which $1 \mu l$ was injected.

Analysis was done on a Thermo Finnigan Focus GC (Thermo Electron S.p.A, Strada Rivoltana, Milan, Italy) equipped with a flame ionization detector using a BPX70 capillary column (60 $\mathrm{m} \times 0.25 \mathrm{~mm}$ internal diameter, $0.25 \mu \mathrm{m}$ film, SGE International Pty Ltd, Victoria, Australia). Gas flow rates were $20 \mathrm{ml} / \mathrm{min}$ for hydrogen, $200 \mathrm{ml} / \mathrm{min}$ for air and $25 \mathrm{ml} / \mathrm{min}$ for nitrogen carrier gas. Temperature programming was linear at $7^{\circ} \mathrm{C} / \mathrm{min}$, with an initial temperature of $60{ }^{\circ} \mathrm{C}$ and a final temperature of $160{ }^{\circ} \mathrm{C}$. The injector temperature was $220^{\circ} \mathrm{C}$ (split flow 20:120) and the detector temperature was $260{ }^{\circ} \mathrm{C}$. The FAMEs were identified by comparing the retention times to those of a standard FAME mixture (Supelco ${ }^{\mathrm{TM}} 37$ Component FAME Mix, $10 \mathrm{mg} / \mathrm{ml}$ in $\mathrm{CH}_{2} \mathrm{Cl}_{2}$, Catalogue Number 47885-U, Supelco, Bellefonte, USA).

From the lipid extraction used for the fatty acid determination, $1 \mathrm{ml}$ was used for cholesterol determination. Stigmasterol was added as internal standard before drying the sub-sample under nitrogen $\left(\mathrm{C}_{29} \mathrm{H}_{48} \mathrm{O}\right.$, Sigma-Aldrich Inc.). After drying, $0.5 \mathrm{ml}$ of a $6 \%$ ethanolic potassium hydroxide $(\mathrm{KOH})$ solution was used to saponify the lipid fraction in a heating block for $1 \mathrm{~h}$ at $70^{\circ} \mathrm{C}$. After cooling, distilled water and hexane were added and the top phase was transferred to a spotting tube and dried under nitrogen. Fifty microliters of hexane was added to the dried sample of which $1 \mu \mathrm{l}$ was injected.

Analysis was done on a Thermo Finnigan Focus GC equipped with a flame ionized detector using a DB-17 capillary column $(15 \mathrm{~m} \times 0.53 \mathrm{~mm}$ internal diameter, $1.50 \mu \mathrm{m}$ film, Agilent Technologies Inc., CA, USA). Gas flow rates were $20 \mathrm{ml} / \mathrm{min}$ for hydrogen, $200 \mathrm{ml} / \mathrm{min}$ for air and $25 \mathrm{ml} / \mathrm{min}$ for nitrogen carrier gas. Temperature settings were as follows: injector, $220{ }^{\circ} \mathrm{C}$, oven, $250{ }^{\circ} \mathrm{C}$ and detector, $265{ }^{\circ} \mathrm{C}$. 


\subsubsection{Amino acid profile}

Amino acids were determined on cooked dried, defatted organ samples. Samples were hydrolyzed (AOAC official method 994.12, 2003) with $6 \mathrm{M} \mathrm{HCl}$ in a sealed tube under nitrogen for $24 \mathrm{~h}$ at $110^{\circ} \mathrm{C}$. Thereafter samples were diluted and derivatized using the EZ:Faast LC method (Phenomenex, USA). EZ:Faast consists of a solid phase extraction step followed by a derivatization step and a liquid-liquid extraction step to get rid of interfering compounds in the matrix. In the solid phase extraction step the samples are pulled through a sorbent tip that binds the amino acids whilst the remaining interfering compounds flow through. The amino acids are then derivatized allowing them to migrate to the organic layer which is removed, dried, redissolved and subject to Liquid chromatography-mass spectrometry-mass spectrometry (LC/MS/MS) analysis. In addition a daughter ion is formed that makes LC/MS/MS analysis possible. Labelled methionine-d3 was included as internal standard. A Waters Micromass Quattro Micro LC/MS/MS triple quadrupole mass spectrometer (mass range: 2-2000 m/z), complete with Waters Alliance 2695 Separations Module (HPLC) was used for the determination of amino acid composition (Waters Corporation, Milford, USA).

\subsection{Statistical analyses}

The data was analysed using a one way analysis of variance per organ with breed (Dorper or Merino) as the main effect. The results were generated using PROC GLM of SAS software, Version 9.1.3 of the SAS Institute Inc. (2002-2005). The model was:

$\mathrm{Yij}=\mu+\mathrm{ai}+\varepsilon \mathrm{ij}$

Where

yi $\mathrm{j}=\mathrm{jthobservationinbreedi}$;

$\mu=$ commonmean;

ai $=$ effectofbreedi;

$\varepsilon \mathrm{i} \mathrm{j}=\mathrm{j}$ thresidualofbreedj.

Differences within the main effect were accepted as being significant if the probability of rejection of $H_{o}$ was less than $5 \%(\mathrm{P}<0.05)$.

\section{Results and discussion}

\subsection{Proximate composition}

The proximate compositions of the nine organs and the effect of breed thereon are given in Table 1. The moisture content of the brain, kidney and liver are similar to those reported by Mustafa (1988) for raw and cooked mutton brain, kidney and liver. However, Mustafa (1988) reported lower moisture values for mutton tongue and found that cooking significantly reduced the moisture content of mutton heart, which he reported as being $80.2 \%$ in raw heart and $67.9 \%$ in cooked heart. Although the samples were cooked in this investigation, the moisture exuding from the organs during the cooking process were retained in the bag and remixed during the homogenizing of the samples - this was done as it is argued that the organs are regularly consumed as stews in South Africa and this method would give the most representative data as pertaining to their nutritional value. Sokolov et al. (1970) and Kiernat et al. (1964) reported moisture values (67.9\% and $69.5 \%$, respectively) for raw lamb tongue similar to that analysed in the current investigation. Abdullah (2008) also reported similar moisture contents for liver, spleen, heart and kidney to that in the current study as did Park et al. (1991) for goat heart, kidney and lung. 


\begin{tabular}{|c|c|c|c|c|c|c|c|c|}
\hline \multirow[t]{2}{*}{ Breed } & \multicolumn{2}{|l|}{ Moisture } & \multicolumn{2}{|l|}{ Protein } & \multicolumn{2}{|l|}{ Fat } & \multicolumn{2}{|l|}{ Ash } \\
\hline & Dorper & Merino & Dorper & Merino & Dorper & Merino & Dorper & Merino \\
\hline Brain & $77.8 \pm 0.29$ & $78.0 \pm 0.29$ & $10.1^{\mathrm{a}} \pm 0.32$ & $8.7^{b} \pm 0.32$ & $10.1^{\mathrm{b}} \pm 0.30$ & $11.9^{\mathrm{a}} \pm 0.30$ & $2.0 \pm 0.06$ & $2.0 \pm 0.06$ \\
\hline Heart & $66.8^{\mathrm{b}} \pm 0.71$ & $68.9^{\mathrm{a}} \pm 0.71$ & $15.2^{\mathrm{a}} \pm 0.50$ & $13.5^{\mathrm{b}} \pm 0.50$ & $16.4 \pm 0.84$ & $16.4 \pm 0.84$ & $0.9 \pm 0.06$ & $0.9 \pm 0.06$ \\
\hline Liver & $66.7 \pm 0.68$ & $66.9 \pm 0.68$ & $18.8 \pm 0.81$ & $20.9 \pm 0.81$ & $11.8^{\mathrm{a}} \pm 0.59$ & $9.7^{b} \pm 0.59$ & $1.9 \pm 0.11$ & $1.6 \pm 0.11$ \\
\hline Lung & $77.9 \pm 1.07$ & $76.0 \pm 1.07$ & $15.6 \pm 0.97$ & $17.6 \pm 0.97$ & $4.6 \pm 0.09$ & $4.6 \pm 0.09$ & $1.1^{\mathrm{a}} \pm 0.03$ & $1.1^{\mathrm{b}} \pm 0.03$ \\
\hline Spleen & $75.3^{\mathrm{b}} \pm 0.38$ & $77.2^{a} \pm 0.38$ & $20.4^{\mathrm{a}} \pm 0.23$ & $16.1^{\mathrm{b}} \pm 0.23$ & $2.9^{\mathrm{b}} \pm 0.20$ & $4.3^{\mathrm{a}} \pm 0.20$ & $1.7 \pm 0.19$ & $1.4 \pm 0.19$ \\
\hline Stomach & $82.7^{\mathrm{a}} \pm 0.74$ & $79.8^{\mathrm{b}} \pm 0.74$ & $14.8 \pm 0.62$ & $15.5 \pm 0.62$ & $1.7^{\mathrm{b}} \pm 0.18$ & $3.1^{\mathrm{a}} \pm 0.18$ & $0.9^{\mathrm{a}} \pm 0.04$ & $0.7^{\mathrm{b}} \pm 0.04$ \\
\hline
\end{tabular}

Mustafa (1988) also found similar fat values for brain but found the fat content of the heart, liver and kidney to be much lower than reported in this study. Mustafa (1988) found the fat content of raw and cooked tongue to be $26.2 \%$ and $22.8 \%$ respectively, which is considerably higher than those found in the current study. Sokolov et al. (1970) and Kiernat et al. (1964) reported similar fat values for raw lamb tongue (16.1\% and $15.3 \%$ respectively). Park et al. (1991) recorded considerably lower fat values for goat heart, kidney and lung than in the current study. The authors reported fat contents of $3.3 \%, 3.1 \%$ and $4.3 \%$ for goat, liver, kidney and heart, respectively. Abdullah (2008) also reported considerably lower fat contents for sheep liver (3.2\%) and heart (6.6\%).

The organs differed in proximate composition with the testicles having the highest moisture content, liver having the highest protein content, heart having the highest fat content and the brain having the highest ash content (Table 1). Conversely, the tongue had the lowest moisture content, the brain the lowest protein content and the stomach the lowest fat as well as ash content.

Differences in proximate composition were also found between breeds for all the organs. Merino heart, spleen and testicles had higher moisture contents than those of the Dorper whilst Dorper brain, heart, kidney, spleen and testicles had higher protein contents than those of the Merino. With the exception of the liver, Merino organs tended to have a higher fat content than Dorper organs. These breed differences may be attributed to the Blackhead Persian forefather of the Dorper which is a leaner sheep breed with more localised fat when compared to the Merino. Ash content only differed between breed for the lungs and stomach with Dorper lungs and stomach having a higher ash content.

Dorper and Merino heart, and Merino tongue, were found to have a higher fat content, whereas spleen, stomach and testicles of both breeds were generally found to contain the lowest total fat percentage. Low fat products must contain less than $3 \mathrm{~g}$ of fat per serving (Wylie-Rosett, 2002), placing Dorper spleen and stomach within the low fat category based on a $100 \mathrm{~g}$ serving. However, associations between total fat intake and coronary heart disease are primarily mediated through the saturated and unsaturated fatty acid components (Hodson et al., 2001 and Shrapnel et al., 1992).

\subsection{Fatty acid profile and cholesterol content}

The fatty acid profiles and cholesterol contents of the different organs from the two breeds are shown in Table 2. In all the organs, palmitic and stearic acids were the dominant SFA present. With the exception of the kidney, liver, stomach and testicle, no differences between breeds were found for any of the total saturated fatty acids (SFA). In the kidney, the Dorper had significantly higher palmitic acid (C16:0) levels than the Merino whilst in the testicle the stearic acid (C18:0) levels were lower in the Dorper. The concentrations and differences in C21:0 in the liver, and $\mathrm{C} 14: 0$ and $\mathrm{C} 15: 0$ in the stomach were so small that their biological significance is questionable. 
Fatty acid composition (\%) and cholesterol content ( $\mathrm{mg} / 100 \mathrm{~g})$ of Dorper and Merino organs.

\begin{tabular}{|c|c|c|c|c|c|c|c|c|c|c|}
\hline Fatty Acid & Breed & Brain & Heart & Kidney & Liver & Lung & Spleen & Stomach & Testicle & Tongue \\
\hline \multicolumn{11}{|l|}{ Saturated fatty acids } \\
\hline \multirow[t]{2}{*}{ C14:0 } & Dorper & $0.3 \pm 0.06$ & $1.7 \pm 0.52$ & $0.8 \pm 0.14$ & $0.6 \pm 0.24$ & $0.6 \pm 0.12$ & $1.1 \pm 0.22$ & $0.4^{\mathrm{b}} \pm 0.21$ & $1.7 \pm 0.63$ & $3.6 \pm 0.97$ \\
\hline & Merino & $0.2 \pm 0.06$ & $2.2 \pm 0.52$ & $0.6 \pm 0.14$ & $0.8 \pm 0.24$ & $0.5 \pm 0.15$ & $1.0 \pm 0.22$ & $1.3^{\mathrm{a}} \pm 0.19$ & $0.5 \pm 0.78$ & $1.6 \pm 0.97$ \\
\hline \multirow[t]{2}{*}{$\mathrm{C} 15: 0$} & Dorper & $0.2 \pm 0.09$ & $0.4 \pm 0.10$ & $0.4 \pm 0.06$ & $0.4 \pm 0.07$ & $0.5 \pm 0.07$ & $0.5 \pm 0.06$ & $0.4^{\mathrm{b}} \pm 0.09$ & $0.5 \pm 0.10$ & $0.7 \pm 0.19$ \\
\hline & Merino & $0.2 \pm 0.09$ & $0.7 \pm 0.10$ & $0.4 \pm 0.06$ & $0.4 \pm 0.07$ & $0.6 \pm 0.08$ & $0.5 \pm 0.06$ & $0.8^{\mathrm{a}} \pm 0.09$ & $0.3 \pm 0.12$ & $0.4 \pm 0.19$ \\
\hline \multirow[t]{2}{*}{$\mathrm{C} 16: 0$} & Dorper & $18.1 \pm 1.08$ & $31.5 \pm 3.55$ & $23.8^{\mathrm{a}} \pm 1.23$ & $20.4 \pm 4.32$ & $30.7 \pm 1.36$ & $23.5 \pm 1.75$ & $20.2 \pm 1.46$ & $31.6 \pm 2.93$ & $30.6 \pm 5.89$ \\
\hline & Merino & $17.6 \pm 1.08$ & $30.7 \pm 3.55$ & $19.9^{\mathrm{b}} \pm 1.23$ & $20.8 \pm 4.32$ & $25.8 \pm 1.67$ & $22.3 \pm 1.75$ & $23.5 \pm 1.33$ & $24.9 \pm 3.59$ & $22.1 \pm 5.89$ \\
\hline \multirow[t]{2}{*}{ C18:0 } & Dorper & $27.0 \pm 2.13$ & $36.3 \pm 4.01$ & $19.7 \pm 2.78$ & $26.7 \pm 3.55$ & $17.8 \pm 0.76$ & $26.9 \pm 1.17$ & $28.0 \pm 1.82$ & $15.5^{\mathrm{b}} \pm 0.76$ & $16.6 \pm 6.21$ \\
\hline & Merino & $26.2 \pm 2.13$ & $34.0 \pm 4.01$ & $22.7 \pm 2.78$ & $23.5 \pm 3.55$ & $18.2 \pm 0.93$ & $26.7 \pm 1.17$ & $25.2 \pm 1.66$ & $18.8^{\mathrm{a}} \pm 0.94$ & $20.2 \pm 6.21$ \\
\hline \multirow[t]{2}{*}{$\mathrm{C} 20: 0$} & Dorper & nd & nd & $0.2 \pm 0.08$ & nd & $0.2 \pm 0.04$ & $0.2 \pm 0.07$ & $0.2 \pm 0.03$ & $0.2 \pm 0.03$ & $0.1 \pm 0.03$ \\
\hline & Merino & nd & nd & $0.2 \pm 0.08$ & nd & $0.2 \pm 0.05$ & $0.3 \pm 0.07$ & $0.2 \pm 0.03$ & $0.2 \pm 0.03$ & $0.1 \pm 0.03$ \\
\hline \multirow[t]{2}{*}{$\mathrm{C} 21: 0$} & Dorper & $0.1 \pm 0.02$ & $0.1 \pm 0.14$ & $0.2 \pm 0.03$ & $0.2^{\mathrm{a}} \pm 0.01$ & $0.3 \pm 0.03$ & $0.1 \pm 0.08$ & $0.2 \pm 0.03$ & $0.1 \pm 0.03$ & $0.1 \pm 0.02$ \\
\hline & Merino & $0.2 \pm 0.02$ & $0.3 \pm 0.14$ & $0.2 \pm 0.03$ & $0.1^{\mathrm{b}} \pm 0.01$ & $0.3 \pm 0.03$ & $0.3 \pm 0.08$ & $0.2 \pm 0.02$ & $0.1 \pm 0.03$ & $0.1 \pm 0.02$ \\
\hline \multirow[t]{2}{*}{ C22:0 } & Dorper & $1.0 \pm 0.17$ & $0.1 \pm 0.11$ & $0.6 \pm 0.10$ & $1.7 \pm 0.28$ & $1.3 \pm 0.14$ & $1.2 \pm 0.13$ & $0.5 \pm 0.07$ & $2.8 \pm 0.55$ & $0.1 \pm 0.03$ \\
\hline & Merino & $1.0 \pm 0.17$ & $0.4 \pm 0.11$ & $0.6 \pm 0.10$ & $0.9 \pm 0.28$ & $1.4 \pm 0.17$ & $0.9 \pm 0.13$ & $0.3 \pm 0.06$ & $3.2 \pm 0.67$ & $0.1 \pm 0.03$ \\
\hline \multirow[t]{2}{*}{ C24:0 } & Dorper & $0.1 \pm 0.03$ & $0.0^{\mathrm{b}} \pm 0.01$ & $0.8 \pm 0.17$ & $1.1 \pm 0.20$ & $0.6 \pm 0.09$ & $0.5 \pm 0.07$ & $0.3 \pm 0.04$ & $0.1 \pm 0.02$ & $0.1 \pm 0.02$ \\
\hline & Merino & $0.1 \pm 0.03$ & $0.1^{\mathrm{a}} \pm 0.01$ & $0.9 \pm 0.17$ & $0.7 \pm 0.20$ & $0.7 \pm 0.10$ & $0.6 \pm 0.07$ & $0.2 \pm 0.03$ & $0.2 \pm 0.03$ & $0.0 \pm 0.02$ \\
\hline \multicolumn{11}{|c|}{ Monounsaturated fatty acids } \\
\hline \multirow[t]{2}{*}{ C16:1 } & Dorper & $0.3 \pm 0.04$ & $0.5 \pm 0.14$ & $1.0 \pm 0.26$ & $0.8 \pm 0.09$ & $1.1_{\mathrm{a}} \pm 0.10$ & $0.7 \pm 0.08$ & $0.8^{\mathrm{b}} \pm 0.15$ & $1.4^{\mathrm{a}} \pm 0.13$ & $1.4 \pm 0.43$ \\
\hline & Merino & $0.4 \pm 0.04$ & $0.5 \pm 0.14$ & $0.9 \pm 0.26$ & $0.8 \pm 0.09$ & $0.5_{b} \pm 0.12$ & $0.7 \pm 0.08$ & $1.3^{\mathrm{a}} \pm 0.13$ & $0.9^{\mathrm{b}} \pm 0.16$ & $1.3 \pm 0.43$ \\
\hline $\mathrm{C} 18: 1 \mathrm{n} 9 \mathrm{c}$ & Dorper & $25.2 \pm 1.41$ & $26.2 \pm 5.46$ & $28.7 \pm 3.68$ & $22.9 \pm 6.19$ & $24.9 \pm 0.66$ & $26.3 \pm 2.10$ & $36.2 \pm 1.98$ & $28.6 \pm 2.36$ & $42.0 \pm 13.29$ \\
\hline & Merino & $26.9 \pm 1.41$ & $20.2 \pm 5.46$ & $30.3 \pm 3.68$ & $31.9 \pm 6.19$ & $26.1 \pm 0.80$ & $29.0 \pm 2.10$ & $36.9 \pm 1.81$ & $29.7 \pm 2.89$ & $49.1 \pm 13.29$ \\
\hline $\mathrm{C} 18 \mathrm{1} \operatorname{\mathrm {n}9\mathrm {t}}$ & Dorper & $0.2^{\mathrm{b}} \pm 0.02$ & $1.4 \pm 0.80$ & $1.8 \pm 0.40$ & $0.7 \pm 0.18$ & $2.0 \pm 0.42$ & $2.6 \pm 0.33$ & $3.8^{\mathrm{a}} \pm 0.58$ & $1.9 \pm 0.19$ & $2.2 \pm 0.79$ \\
\hline & Merino & $0.3^{\mathrm{a}} \pm 0.02$ & $2.8 \pm 0.80$ & $2.3 \pm 0.40$ & $0.7 \pm 0.18$ & $1.9 \pm 0.51$ & $2.2 \pm 0.33$ & $0.8^{\mathrm{b}} \pm 0.53$ & $1.7 \pm 0.24$ & $1.0 \pm 0.79$ \\
\hline $\mathrm{C} 20: 1$ & Dorper & $0.2 \pm 0.03$ & $0.1^{\mathrm{b}} \pm 0.03$ & $0.1 \pm 0.02$ & $0.1 \pm 0.01$ & $0.5 \pm 0.04$ & $0.2 \pm 0.02$ & $0.2^{\mathrm{a}} \pm 0.02$ & $0.1 \pm 0.01$ & $0.1 \pm 0.03$ \\
\hline & Merino & $0.3 \pm 0.03$ & $0.2^{\mathrm{a}} \pm 0.03$ & $0.1 \pm 0.02$ & $0.1 \pm 0.01$ & $0.5 \pm 0.05$ & $0.2 \pm 0.02$ & $0.2^{\mathrm{b}} \pm 0.02$ & $0.1 \pm 0.01$ & $0.1 \pm 0.03$ \\
\hline $\mathrm{C} 22: 1 \mathrm{n} 9$ & Dorper & $0.0 \pm 0.01$ & $0.0 \pm 0.01$ & $0.1 \pm 0.02$ & $0.1 \pm 0.01$ & $0.1 \pm 0.01$ & $0.1 \pm 0.03$ & $0.1 \pm 0.02$ & $0.1 \pm 0.02$ & $0.1 \pm 0.02$ \\
\hline & Merino & $0.0 \pm 0.01$ & $0.1 \pm 0.01$ & $0.1 \pm 0.02$ & $0.1 \pm 0.01$ & $0.1 \pm 0.02$ & $0.1 \pm 0.03$ & $0.1 \pm 0.02$ & $0.1 \pm 0.02$ & $0.0 \pm 0.02$ \\
\hline $\mathrm{C} 24: 1$ & Dorper & $4.1 \pm 0.47$ & $0.0 \pm 0.03$ & $0.3 \pm 0.06$ & $0.2 \pm 0.03$ & $1.1 \pm 0.18$ & $1.0^{\mathrm{a}} \pm 0.14$ & $0.2 \pm 0.25$ & $0.3 \pm 0.23$ & $0.0 \pm 0.02$ \\
\hline & Merino & $5.0 \pm 0.47$ & $0.1 \pm 0.03$ & $0.4 \pm 0.06$ & $0.2 \pm 0.03$ & $1.4 \pm 0.22$ & $0.5^{\mathrm{b}} \pm 0.14$ & $0.4 \pm 0.22$ & $1.0 \pm 0.28$ & $0.0 \pm 0.02$ \\
\hline Polyunsc & & & & & & & & & & \\
\hline $\mathrm{C} 18: 2 \mathrm{n} 6 \mathrm{c}$ & Dorper & $0.7 \pm 0.10$ & $1.1^{\mathrm{b}} \pm 0.70$ & $12.6 \pm 0.98$ & $12.8 \pm 2.13$ & $6.6 \pm 0.62$ & $5.5 \pm 0.90$ & $4.9 \pm 0.60$ & $3.1 \pm 0.36$ & $1.3 \pm 1.11$ \\
\hline & Merino & $0.7 \pm 0.10$ & $5.0^{\mathrm{a}} \pm 0.70$ & $9.6 \pm 0.98$ & $10.0 \pm 2.13$ & $5.6 \pm 0.76$ & $5.4 \pm 0.90$ & $5.4 \pm 0.55$ & $3.7 \pm 0.44$ & $2.9 \pm 1.11$ \\
\hline C18:2n6t & Dorper & $0.1 \pm 0.02$ & $0.2^{\mathrm{b}} \pm 0.07$ & $0.2 \pm 0.05$ & $0.3 \pm 0.05$ & $0.3 \pm 0.02$ & $0.3 \pm 0.02$ & $0.4 \pm 0.05$ & $0.2 \pm 0.02$ & $0.2 \pm 0.10$ \\
\hline & Merino & $0.1 \pm 0.02$ & $0.6^{\mathrm{a}} \pm 0.07$ & $0.3 \pm 0.05$ & $0.3 \pm 0.05$ & $0.3 \pm 0.02$ & $0.3 \pm 0.02$ & $0.4 \pm 0.04$ & $0.3 \pm 0.02$ & $0.3 \pm 0.10$ \\
\hline C18:3n6 & Dorper & $0.0 \pm 0.02$ & $0.2^{\mathrm{b}} \pm 0.12$ & $1.5 \pm 0.39$ & $1.4 \pm 0.34$ & $0.3^{\mathrm{b}} \pm 0.03$ & $0.4^{\mathrm{b}} \pm 0.08$ & $0.8^{\mathrm{b}} \pm 0.09$ & $0.4 \pm 0.07$ & $0.4 \pm 0.08$ \\
\hline & Merino & $0.1 \pm 0.02$ & $0.8^{\mathrm{a}} \pm 0.12$ & $1.6 \pm 0.39$ & $1.9 \pm 0.34$ & $0.4^{\mathrm{a}} \pm 0.04$ & $0.8^{\mathrm{a}} \pm 0.08$ & $1.1^{\mathrm{a}} \pm 0.08$ & $0.5 \pm 0.08$ & $0.4 \pm 0.08$ \\
\hline $\mathrm{C} 18: 3 \mathrm{n} 3$ & Dorper & $2.5 \pm 0.26$ & $0.0^{\mathrm{b}} \pm 0.01$ & $0.2 \pm 0.03$ & $0.2 \pm 0.01$ & $0.5 \pm 0.04$ & $0.4 \pm 0.03$ & $0.2 \pm 0.03$ & $0.2 \pm 0.02$ & $0.1 \pm 0.01$ \\
\hline & Merino & $2.6 \pm 0.26$ & $0.1^{\mathrm{a}} \pm 0.01$ & $0.2 \pm 0.03$ & $0.1 \pm 0.01$ & $0.5 \pm 0.05$ & $0.3 \pm 0.03$ & $0.2 \pm 0.03$ & $0.2 \pm 0.02$ & $0.1 \pm 0.01$ \\
\hline $\mathrm{C} 20: 2$ & Dorper & $0.2 \pm 0.03$ & $0.0 \pm 0.05$ & $0.2 \pm 0.03$ & $0.2^{\mathrm{a}} \pm 0.02$ & $0.3 \pm 0.03$ & $0.3 \pm 0.05$ & $0.1 \pm 0.02$ & $0.2 \pm 0.03$ & $0.1 \pm 0.02$ \\
\hline & Merino & $0.2 \pm 0.03$ & $0.1 \pm 0.05$ & $0.2 \pm 0.03$ & $0.1^{\mathrm{b}} \pm 0.02$ & $0.3 \pm 0.04$ & $0.2 \pm 0.05$ & $0.1 \pm 0.01$ & $0.2 \pm 0.04$ & $0.0 \pm 0.02$ \\
\hline $\mathrm{C} 20: 3 \mathrm{n} 6$ & Dorper & $5.2 \pm 0.92$ & $0.2^{\mathrm{b}} \pm 0.12$ & $4.9 \pm 0.93$ & $5.6 \pm 1.09$ & $6.6^{\mathrm{b}} \pm 0.94$ & $6.6 \pm 0.72$ & $1.3 \pm 0.22$ & $4.1 \pm 0.80$ & $0.2 \pm 0.04$ \\
\hline & Merino & $5.1 \pm 0.92$ & $0.9^{\mathrm{a}} \pm 0.12$ & $6.8 \pm 0.93$ & $4.3 \pm 1.09$ & $10.2^{\mathrm{a}} \pm 1.16$ & $6.2 \pm 0.72$ & $1.1 \pm 0.20$ & $6.4 \pm 0.98$ & $0.1 \pm 0.04$ \\
\hline $\mathrm{C} 20: 3 \mathrm{n} 3$ & Dorper & $0.5 \pm 0.20$ & $0.0 \pm 0.01$ & $0.3 \pm 0.06$ & $0.1 \pm 0.01$ & $0.9 \pm 0.06$ & $0.3 \pm 0.04$ & $0.2 \pm 0.03$ & $0.1 \pm 0.02$ & $0.0 \pm 0.02$ \\
\hline & Merino & $0.9 \pm 0.20$ & $0.1 \pm 0.01$ & $0.3 \pm 0.06$ & $0.1 \pm 0.01$ & $0.9 \pm 0.08$ & $0.2 \pm 0.04$ & $0.1 \pm 0.03$ & $0.1 \pm 0.02$ & $0.0 \pm 0.02$ \\
\hline $\mathrm{C} 20: 4 \mathrm{n} 6$ & Dorper & $0.8 \pm 0.09$ & $0.0 \pm 0.04$ & $0.1 \pm 0.02$ & $0.1^{\mathrm{a}} \pm 0.01$ & $0.2 \pm 0.04$ & $0.1 \pm 0.03$ & $0.1 \pm 0.02$ & $0.2 \pm 0.02$ & $0.1 \pm 0.02$ \\
\hline & Merino & $0.9 \pm 0.09$ & $0.1 \pm 0.04$ & $0.1 \pm 0.02$ & $0.1^{\mathrm{b}} \pm 0.01$ & $0.4 \pm 0.05$ & $0.2 \pm 0.03$ & $0.1 \pm 0.02$ & $0.1 \pm 0.03$ & $0.0 \pm 0.02$ \\
\hline $\mathrm{C} 20: 5 \mathrm{n} 3$ & Dorper & $2.5 \pm 0.32$ & $0.0 \pm 0.01$ & $0.4 \pm 0.06$ & $0.4^{\mathrm{a}} \pm 0.04$ & $1.0 \pm 0.10$ & $0.3 \pm 0.04$ & $0.1 \pm 0.03$ & $0.2 \pm 0.04$ & $0.0 \pm 0.02$ \\
\hline & Merino & $2.6 \pm 0.32$ & $0.1 \pm 0.01$ & $0.3 \pm 0.06$ & $0.2^{\mathrm{b}} \pm 0.04$ & $1.2 \pm 0.12$ & $0.3 \pm 0.04$ & $0.1 \pm 0.03$ & $0.2 \pm 0.05$ & $0.0 \pm 0.02$ \\
\hline $\mathrm{C} 22: 2$ & Dorper & $0.4 \pm 0.10$ & $0.0 \pm 0.02$ & $0.3 \pm 0.04$ & $0.6 \pm 0.07$ & $0.7 \pm 0.05$ & $0.3 \pm 0.05$ & $0.2 \pm 0.03$ & $0.1 \pm 0.01$ & $0.1 \pm 0.02$ \\
\hline & Merino & $0.6 \pm 0.10$ & $0.1 \pm 0.02$ & $0.3 \pm 0.04$ & $0.4 \pm 0.07$ & $0.6 \pm 0.06$ & $0.3 \pm 0.05$ & $0.1 \pm 0.02$ & $0.1 \pm 0.02$ & $0.0 \pm 0.02$ \\
\hline $\mathrm{C} 22: 6 \mathrm{n} 3$ & Dorper & $10.2 \pm 1.71$ & $0.1 \pm 0.04$ & $0.8 \pm 0.19$ & $2.7 \pm 0.61$ & $1.0 \pm 0.15$ & $0.8 \pm 0.13$ & $0.3 \pm 0.05$ & $6.3 \pm 1.29$ & $0.1 \pm 0.03$ \\
\hline & Merino & $7.8 \pm 1.71$ & $0.1 \pm 0.04$ & $1.0 \pm 0.19$ & $1.8 \pm 0.61$ & $1.4 \pm 0.19$ & $0.8 \pm 0.13$ & $0.2 \pm 0.04$ & $6.5 \pm 1.58$ & $0.1 \pm 0.03$ \\
\hline SFA & Dorper & $46.8 \pm 2.69$ & $70.0 \pm 5.28$ & $46.5 \pm 2.77$ & $51.0 \pm 7.37$ & $51.9 \pm 1.38$ & $53.9 \pm 2.04$ & $50.2 \pm 2.47$ & $52.5 \pm 3.52$ & $51.9 \pm 12.52$ \\
\hline & Merino & $45.5 \pm 2.69$ & $68.2 \pm 5.28$ & $45.4 \pm 2.77$ & $47.2 \pm 7.37$ & $47.7 \pm 1.69$ & $52.3 \pm 2.04$ & $51.5 \pm 2.25$ & $48.2 \pm 4.31$ & $44.5 \pm 12.52$ \\
\hline MUFA & Dorper & $29.9 \pm 1.25$ & $26.8 \pm 5.37$ & $30.2 \pm 3.79$ & $24.1 \pm 6.12$ & $27.7 \pm 0.71$ & $28.2 \pm 2.04$ & $37.6 \pm 2.09$ & $30.5 \pm 2.43$ & $43.5 \pm 12.97$ \\
\hline & Merino & $32.5 \pm 1.25$ & $21.1 \pm 5.37$ & $31.8 \pm 3.79$ & $33.0 \pm 6.12$ & $28.7 \pm 0.87$ & $30.6 \pm 2.04$ & $38.9 \pm 1.91$ & $31.8 \pm 2.98$ & $50.6 \pm 12.97$ \\
\hline PUFA & Dorper & $22.9 \pm 3.18$ & $1.8^{\mathrm{b}} \pm 0.80$ & $21.2 \pm 0.86$ & $24.0 \pm 3.86$ & $18.1 \pm 1.58$ & $14.9 \pm 1.58$ & $8.0 \pm 0.89$ & $14.8 \pm 2.44$ & $2.2 \pm 1.14$ \\
\hline & Merino & $21.4 \pm 3.18$ & $7.3^{\mathrm{a}} \pm 0.80$ & $20.2 \pm 0.86$ & $18.9 \pm 3.86$ & $21.5 \pm 1.93$ & $14.6 \pm 1.58$ & $8.4 \pm 0.82$ & $18.1 \pm 2.99$ & $3.7 \pm 1.14$ \\
\hline PUFA:SFA & Dorper & 0.5 & 0 & 0.5 & 0.5 & 0.4 & 0.3 & 0.2 & 0.3 & 0 \\
\hline & Merino & 0.5 & 0.1 & 0.5 & 0.4 & 0.5 & 0.3 & 0.2 & 0.4 & 0.1 \\
\hline$(n-6) /(n-3)$ & Dorper & 0.4 & 9 & 11.4 & 6 & 4.1 & 7.4 & 9.5 & 1.1 & 7.8 \\
\hline & Merino & 0.5 & 20.4 & 10.2 & 7.3 & 4.1 & 7.5 & 13.4 & 1.5 & 18.9 \\
\hline Cholesterol (mg/100 g) & Dorper & $5238.3 \pm 157.70$ & $56.5^{\mathrm{a}} \pm 2.14$ & $226.2^{\mathrm{a}} \pm 7.73$ & $168.2^{\mathrm{b}} \pm 11.66$ & $201.8 \pm 17.6$ & $188.2 \pm 11.5$ & $30.9 \pm 1.75$ & $89.2 \pm 7.47$ & $46.6 \pm 3.66$ \\
\hline & Merino & $5638.3 \pm 157.70$ & $48.6^{\mathrm{b}} \pm 2.14$ & $155.6^{\mathrm{b}} \pm 7.73$ & $205.5^{\mathrm{a}} \pm 11.66$ & $175.7 \pm 21.56$ & $177.4 \pm 11.50$ & $35.8 \pm 1.75$ & $98.9 \pm 8.19$ & $51.3 \pm 3.66$ \\
\hline
\end{tabular}

nd $=$ non detected.

Although breed had no effect on the total mono unsaturated fatty acids (MUFA) present, there were a few fatty acids that did differ between breeds within some of the organs (Table 2). Similar to the SFA, most of the differences are so small that their biological significance is questionable. However, of these differences, the significantly higher eladic acid (C18:1ngt) in the Dorper stomach is worth noting, although the reason for this is unknown. For all the organs, oleic acid (C18:1n9c) was the dominant fatty acid (most values being above 25\%) present with the tongue having the highest ( $>42 \%)$ concentration. The brain also had high (4-5\%) levels of nervonic acid (C24:1 n9c).

Breed had no effect on the total polyunsaturated fatty acids (PUFA) except for the heart where the Merino had a higher level than the Dorper ( 7.3 vs $1.8 \%$, respectively). The reason for this is not clear although linoleic acid (C16:2n6c) was the most abundant PUFA. Linoleic acid was also a prominent fatty acid in the other organs as were homo- $\delta$ linoleic acid (C20:3n6c) and cervonic acid (C22:6n3c). Although C20:3n6 differed significantly between breeds in the heart, the levels were $<1 \%$ whilst the significant 
difference between the breeds in the lung were of a higher magnitude with the Dorper having $6.6 \%$ which was nearly half of the $10.2 \%$ of the Merino's lung.

Globally, the PUFA differed between organs with the tongue having the lowest level of PUFA. Total PUFA levels ranged between organs from 2.2\% to 24.0\%. Park and Washington (1993) reported PUFA values of 28.5\%, 23.0\% and 26.9\% for raw goat liver, kidney and heart, respectively which is higher than any of the values found in the current study. Although it should be noted that Park and Washington (1993) performed their analysis on raw samples, whilst the analyses reported here are on cooked samples.

Excessive intake of saturated fatty acids has long been associated with obesity, and to a corresponding risk of the metabolic syndrome (insulin resistance), type 2 diabetes and cardiovascular disease (Siri-Tarino, Sun, Hu, \& Krauss, 2010). In particular, saturated fatty acids have been shown to raise plasma lipids and unfavourably modify serum lipoproteins (increasing total cholesterol (TC) and low density lipoproteins (LDL), although the TC:High Density Lipoprotein (HDL) ratio may remain unchanged as HDL may also increase). Unfavourable TC:HDL ratios are considered a more important cardiovascular risk than total cholesterol or LDL alone (Siri-Tarino et al., 2010). It is recommended by the AHA that a healthy diet should consist of no more than $10 \%$ total caloric intakes being obtained through saturated fats (approximately 33\% total fat intake), and those with raised cholesterol risks should consume less than 7\% (Wylie-Rosett, 2002). Generally, the percentage of saturated fatty acids in the organs assessed were relatively high, and the meat cuts should be considered as high in saturated fats.

Unsaturated fatty acids are widely considered to have a more beneficial biological effect in humans, with many arguing in favour of replacing saturated fats with unsaturated fats, rather than carbohydrates, to cause a favourable change in serum lipid profiles (Hodson et al., 2001). However, there is still debate over whether monounsaturated (MUFAs) or polyunsaturated (PUFAs) fats are a more beneficial option. This study indicates that the organ meat generally has a higher amount of MUFAs compared to PUFAs.

Since SFAs and polyunsaturated fatty acids (PUFAs) are consumed together, their ratio (the P:S ratio) is an important measure of the relative risk factor of the cholesterol content in foodstuff. The higher the P:S ratio, the healthier a foodstuff is considered and the recommended daily allowance of P:S for humans is around 0.45 (Grundy, 1997). The P:S ratio of the Dorper and Merino organs showed considerable variation with Dorper hearts and tongues having the lowest ratio, 0.03 and 0.04 respectively. Dorper and Merino brains had the highest levels of 0.49 and 0.47 , respectively. Park and Washington (1993) reported higher P:S ratios in raw goat liver, kidney and heart (liver: 0.69; kidney: 0.54; heart: 0.67$)$.

The majority of the MUFAs consisted of oleic acid (C18:1n9c), the $n-9$ fatty acid found in high concentrations in olive oil. Oleic acid may be beneficial in reducing blood pressure in hypertensive patients (Terés et al., 2008), and may also inhibit the pathogenesis of adrenoleukodystrophy (ALD). Interestingly, the brain of both breeds was also comprised of approximately 4\% nervonic acid (C24:1). This may also be beneficial in the treatment of demyelinating diseases such as multiple sclerosis and ADL (Sargent, Coupland, \& Wilson, 1994). Furthermore, DHA (C22:6n3), comprising approximately 7-10\% of the brain tissue, may also be beneficial in demyelinating conditions (Di Biase \& Salvati, 1997). Any beneficial effect on ADL and demylination would have to be offset to the unfavourable P:S ratios.

The $n-6$ and $n-3$ fatty are considered essential fatty acids in the human diet since the human body is unable to synthesize these itself. Both $n-6$ and $n-3$ fatty acids have 
prominent roles in physiological function, specifically in cell membrane structure and fluidity, immune system function and blood clotting regulation (Das, 2006). As a result, the relative ratio of these essential fatty acids is deemed to be important. Nutritionists have in recent years recommended an increase in specifically $n-3$ fatty acids since the Western diet appears to be overloaded in $\mathrm{n}-6$ fatty acids which is linked with an increased risk of cardiovascular disease (Harris, Poston, \& Haddock, 2007) and various cancers (Hardman, 2002 and Liu et al., 2001). The $\mathrm{n}-6 / \mathrm{n}-3$ ratio is, as a result, often used as a measure of the health value of foodstuff and a value of less than 5 is recommended (Department of Health, 1994 and Raes et al., 2004). However, a 4:1 ratio has been recommended as optimal in a brain function experiment (Yehuda, Rabinovitz, \& Mostofsky, 1998), and a 2:1 ratio is considered superior for immune function (Grimm et al., 1994). Only the heart and the testicles had ratios for these fatty acids of less than five whilst the remaining organs, for both breeds, had values above five.

The brain and testicles warrant further discussion, as the results showed twice as much $\mathrm{n}$ -3 fatty acids as $\mathrm{n}-6$. The $\mathrm{n}-3$ fats consisted of approximately equal amounts of $\mathrm{C} 18: 3 \mathrm{n} 3 \mathrm{c}$ and $\mathrm{C} 2 \mathrm{O}: 5 \mathrm{n} 3 \mathrm{c}$, with a majority proportion consisting of C22:6n3c. C22:6n3c was also found in significant proportions in testicles of both breeds. C20:5n3c and C22:6n3c are $n-3$ fatty acids found in larger concentrations in the oils of cold water fish, and are the fatty acids most associated with reduced incidence of coronary heart disease, sudden cardiac death, all causes of mortality and nonfatal cardiovascular events. Although the $n-6: n-3$ ratio for brain and testicles is considered to fall within the recommended amount, the $\mathrm{n}-6$ portion of both organs consists of a good proportion of C20:3n6, and this is especially apparent in the brain. C20:3n6 differs from the $\mathrm{n}-6$ fatty acids in that it produces series 1 prostaglandins and thromboxanes and series 3 leukotrienes (Kapoor \& Huang, 2006). C18:3n6, via conversion to C20:3n6 by elongase, is therefore considered to be a regulator of inflammation, alongside $n-3$ fatty acids, whereas $\mathrm{n}-6$ fatty acids are mainly involved in the promotion of inflammation via the production of series 2 and 4 eicosanoids, which is considered to be involved in chronic inflammatory conditions linked to heart disease, diabetes and cancer (Kapoor \& Huang, 2006). These proinflammatory eicosanoids are primarily derived from C20:4n6 (Bagga, Wang, Farias-Eisner, Glaspy, \& Reddy, 2003), which is in very low concentrations in all organs when compared to that of $\mathrm{C} 18: 3 \mathrm{n} 6$ and $\mathrm{C} 18: 2 n 6 \mathrm{c}$. Sheep brain and sheep testicles may be considered to have nutritional benefits for secondary prevention of heart disease based on the polyunsaturated fatty acid concentrations, however, the excessively high cholesterol levels found in the sheep brain would negate this benefit. Sheep brain may be an alternative source for extracts of $\mathrm{C} 2 \mathrm{O}: 5 \mathrm{n} 3 \mathrm{c}$ for nutritional supplements.

Of the organs, only the heart, kidney and liver's cholesterol differed between breeds (Table 2). In the heart, the Dorper only had $8 \mathrm{mg} / 100 \mathrm{~g}$ more cholesterol whilst in the kidney it was substantially higher (226 vs $156 \mathrm{mg} / 100 \mathrm{~g}$ ) but, in the liver, the Dorper has a lower cholesterol level than the Merino (168 vs $206 \mathrm{mg} / 100 \mathrm{~g}$ respectively). Of all the organs, the brain has a much higher level of cholesterol. This is in agreement with Mustafa (1988) and Williams (2007), who both reported significantly higher cholesterol levels in lamb brain when compared to other organs. Mustafa (1988) reported a cholesterol content of $1408.05 \mathrm{mg} / 100 \mathrm{~g}$ in cooked mutton brain whilst Williams (2007) reported a cholesterol content of $1352 \mathrm{mg} / 100 \mathrm{~g}$ in lamb brain, which in both cases are lower than the values found in the current investigation. Mustafa (1988) also reported cholesterol levels of $90.2 \mathrm{mg} / 100 \mathrm{~g}$ for cooked mutton heart, $356.3 \mathrm{mg} / 100 \mathrm{~g}$ for cooked liver, $213.8 \mathrm{mg} / 100 \mathrm{~g}$ for cooked kidney and $192.3 \mathrm{mg} / 100 \mathrm{~g}$ for cooked tongue. Similarly, Williams (2007) reported values of $433 \mathrm{mg} / 100 \mathrm{~g}$ cholesterol in lamb liver, $338 \mathrm{mg} / 100 \mathrm{~g}$ in lamb kidney and $129 \mathrm{mg} / 100 \mathrm{~g}$ in lamb heart. Both authors reported values quite different from those in the current investigation and it may be that the cholesterol content of organs is greatly affected by other factors such as nutrition and age.

\section{https://repository.uwc.ac.za/}


Cholesterol is an essential part of adequate body function, forming an important component of steroid hormones (such as cortisol, testosterone and oestrogens), lipid soluble vitamins (including vitamins $\mathrm{A}, \mathrm{D}, \mathrm{E}$ and $\mathrm{K}$ ) and bile acids. The AHA strongly recommends that dietary cholesterol is reduced to less than $300 \mathrm{mg}$ per day, as cholesterol is not an essential fat. The liver and other organs manufacture cholesterol from saturated fats, and excessive blood cholesterol is more often caused by a diet too high in saturated fats than cholesterol itself (Lichtenstein et al., 2006). The brain of both origins contains an excessively high proportion of cholesterol, and therefore should be eaten sparingly and even avoided completely by diabetics and those considered at risk for cardiovascular disease. Even at the generally lower levels identified by Mustafa (1988) and Williams (2007), the brain should be avoided based on primary and secondary cardiovascular disease prevention recommendations. Furthermore, the kidney, liver, lung and spleen of both breeds should be considered high in cholesterol and therefore should be generally restricted in human diets. Sheep stomach can be considered the better option for cholesterol restricted diets.

\subsection{Amino acid profile}

Significant differences in amino acids levels were also noted between breeds (Table 3). Dorper kidneys had lower levels of eleven of the amino acids tested when compared to the Merino kidneys. Conversely, Dorper liver had higher levels of valine, tyrosine, isoleucine, phenylalanine and leucine than Merino liver. However, leucine levels were lower in Dorper heart, kidney, lung and testicles. Dorper testicles also had lower levels of histidine, methionine, tyrosine, cysteine, isoleucine and phenylalanine than Merino testicles. Hydroxyproline levels were lower in the Dorper brain, kidney and spleen. No differences in amino acids were found between breeds for the stomach and tongue.

\begin{tabular}{|c|c|c|c|c|c|c|c|c|c|c|}
\hline Amino acid & Breed & Brain & Heart & Kidney & Liver & Lung & Spleen & Stomach & Testicle & Tongue \\
\hline \multirow[t]{2}{*}{ Alanine } & Dorper & $3.2 \pm 0.21$ & $2.7 \pm 0.20$ & $3.6 \pm 0.17$ & $3.5 \pm 0.12$ & $4.6 \pm 0.11$ & $4.1 \pm 0.28$ & $4.1 \pm 0.17$ & $4.3 \pm 0.32$ & $3.5 \pm 0.20$ \\
\hline & Merino & $3.5 \pm 0.21$ & $3.0 \pm 0.22$ & $3.9 \pm 0.17$ & $3.4 \pm 0.13$ & $5.0 \pm 0.13$ & $3.8 \pm 0.28$ & $4.1 \pm 0.17$ & $4.1 \pm 0.35$ & $3.1 \pm 0.20$ \\
\hline \multirow[t]{2}{*}{ Threonine } & Dorper & $2.8 \pm 0.17$ & $2.2^{\mathrm{b}} \pm 0.08$ & $2.1^{\mathrm{b}} \pm 0.28$ & $3.3 \pm 0.11$ & $3.0 \pm 0.19$ & $2.8 \pm 0.11$ & $2.8 \pm 0.13$ & $2.6 \pm 0.15$ & $2.3 \pm 0.09$ \\
\hline & Merino & $3.0 \pm 0.17$ & $2.5^{\mathrm{a}} \pm 0.08$ & $3.1^{\mathrm{a}} \pm 0.28$ & $3.0 \pm 0.12$ & $3.5 \pm 0.23$ & $2.8 \pm 0.11$ & $2.6 \pm 0.13$ & $2.9 \pm 0.17$ & $2.3 \pm 0.09$ \\
\hline \multirow[t]{2}{*}{ Serine } & Dorper & $32 \pm 0.22$ & $2.4 \pm 0.08$ & $3.4 \pm 0.16$ & $4.0 \pm 0.19$ & $4.0 \pm 0.21$ & $3.2 \pm 0.16$ & $3.8 \pm 0.18$ & $3.4 \pm 0.35$ & $2.7 \pm 0.14$ \\
\hline & Merino & $3.4 \pm 0.22$ & $2.5 \pm 0.09$ & $3.9 \pm 0.16$ & $3.9 \pm 0.21$ & $4.4 \pm 0.25$ & $3.4 \pm 0.16$ & $3.5 \pm 0.18$ & $3.7 \pm 0.39$ & $2.9 \pm 0.14$ \\
\hline \multirow[t]{2}{*}{ Arginine } & Dorper & $4.9 \pm 0.43$ & $3.7 \pm 0.47$ & $2.9 \pm 0.81$ & $4.5 \pm 0.46$ & $5.3 \pm 0.38$ & $3.8 \pm 0.40$ & $6.1 \pm 0.75$ & $5.2 \pm 0.52$ & $4.6 \pm 0.48$ \\
\hline & Merino & $5.2 \pm 0.43$ & $3.4 \pm 0.51$ & $4.7 \pm 0.81$ & $4.4 \pm 0.50$ & $5.2 \pm 0.46$ & $4.0 \pm 0.40$ & $4.5 \pm 0.75$ & $5.6 \pm 0.57$ & $4.4 \pm 0.48$ \\
\hline \multirow[t]{2}{*}{ Glutamic acid } & Dorper & $6.1 \pm 0.57$ & $7.2^{\mathrm{b}} \pm 0.44$ & $10.0 \pm 0.49$ & $12.6 \pm 0.86$ & $10.8 \pm 0.73$ & $9.7 \pm 0.82$ & $7.7 \pm 0.85$ & $10.5 \pm 1.03$ & $6.0 \pm 0.67$ \\
\hline & Merino & $5.9 \pm 0.57$ & $9.0^{\mathrm{a}} \pm 0.48$ & $11.0 \pm 0.49$ & $10.0 \pm 0.94$ & $11.1 \pm 0.89$ & $11.1 \pm 0.82$ & $8.1 \pm 0.85$ & $12.2 \pm 1.13$ & $6.5 \pm 0.67$ \\
\hline \multirow[t]{2}{*}{ Valine } & Dorper & $2.7 \pm 0.15$ & $2.1 \pm 0.11$ & $3.3 \pm 0.12$ & $3.7^{2} \pm 0.09$ & $3.6^{\mathrm{b}} \pm 0.09$ & $3.5 \pm 0.19$ & $2.8 \pm 0.09$ & $2.5 \pm 0.15$ & $2.5 \pm 0.12$ \\
\hline & Merino & $3.0 \pm 0.15$ & $2.4 \pm 0.12$ & $3.6 \pm 0.12$ & $3.4^{\mathrm{b}} \pm 0.10$ & $3.9^{\mathrm{a}} \pm 0.11$ & $3.4 \pm 0.19$ & $2.6 \pm 0.09$ & $2.7 \pm 0.16$ & $2.3 \pm 0.12$ \\
\hline \multirow[t]{2}{*}{ Histidine } & Dorper & $1.6 \pm 0.12$ & $1.3 \pm 0.07$ & $1.6^{\mathrm{b}} \pm 0.08$ & $2.2 \pm 0.08$ & $2.1^{\mathrm{b}} \pm 0.11$ & $2.3 \pm 0.16$ & $1.3 \pm 0.07$ & $1.2^{\mathrm{b}} \pm 0.05$ & $1.2 \pm 0.08$ \\
\hline & Merino & $12 \pm 0.12$ & $1.4 \pm 0.07$ & $2.0^{\mathrm{a}} \pm 0.08$ & $2.1 \pm 0.09$ & $2.5^{\mathrm{a}} \pm 0.13$ & $2.1 \pm 0.16$ & $1.2 \pm 0.07$ & $1.4^{\mathrm{a}} \pm 0.05$ & $1.2 \pm 0.08$ \\
\hline \multirow{2}{*}{ Aspartic acid } & Dorper & $5.7 \pm 0.46$ & $4.8^{b} \pm 0.18$ & $6.7^{\mathrm{b}} \pm 0.27$ & $8.2 \pm 0.34$ & $7.4 \pm 0.41$ & $6.6 \pm 0.22$ & $6.1 \pm 0.42$ & $7.3 \pm 0.45$ & $4.9 \pm 0.28$ \\
\hline & Merino & $5.9 \pm 0.46$ & $5.7^{\mathrm{a}} \pm 0.19$ & $8.0^{\mathrm{a}} \pm 0.27$ & $7.3 \pm 0.38$ & $8.7 \pm 0.50$ & $72 \pm 0.22$ & $5.9 \pm 0.42$ & $7.9 \pm 0.49$ & $5.4 \pm 0.28$ \\
\hline \multirow[t]{2}{*}{ Lysine } & Dorper & $4.7 \pm 0.31$ & $3.5 \pm 0.20$ & $4.3 \pm 0.30$ & $5.6 \pm 0.21$ & $5.6 \pm 0.26$ & $5.3 \pm 0.26$ & $5.1 \pm 0.21$ & $4.8 \pm 0.23$ & $4.9 \pm 0.23$ \\
\hline & Merino & $4.7 \pm 0.31$ & $4.0 \pm 0.22$ & $5.0 \pm 0.30$ & $5.3 \pm 0.23$ & $5.9 \pm 0.32$ & $5.4 \pm 0.26$ & $5.0 \pm 0.21$ & $5.4 \pm 0.26$ & $5.1 \pm 0.23$ \\
\hline \multirow[t]{2}{*}{ Proline } & Dorper & $2.7 \pm 0.18$ & $2.6 \pm 0.13$ & $3.5^{\mathrm{b}} \pm 0.10$ & $4.0 \pm 0.10$ & $4.5 \pm 0.09$ & $4.0 \pm 0.16$ & $4.9 \pm 0.16$ & $5.5 \pm 0.26$ & $3.3 \pm 0.13$ \\
\hline & Merino & $2.9 \pm 0.18$ & $2.8 \pm 0.14$ & $4.1^{\mathrm{a}} \pm 0.10$ & $3.8 \pm 0.11$ & $4.6 \pm 0.12$ & $4.3 \pm 0.16$ & $4.8 \pm 0.16$ & $5.1 \pm 0.28$ & $3.1 \pm 0.13$ \\
\hline \multirow[t]{2}{*}{ Methionine } & Dorper & $12 \pm 0.06$ & $1.1 \pm 0.04$ & $1.4^{\mathrm{b}} \pm 0.03$ & $1.4 \pm 0.04$ & $1.2 \pm 0.03$ & $1.3 \pm 0.03$ & $1.3 \pm 0.06$ & $1.1^{\mathrm{b}} \pm 0.03$ & $1.2 \pm 0.03$ \\
\hline & Merino & $1.3 \pm 0.06$ & $1.2 \pm 0.05$ & $1.5^{\mathrm{a}} \pm 0.03$ & $1.3 \pm 0.04$ & $1.3 \pm 0.03$ & $1.3 \pm 0.03$ & $1.2 \pm 0.06$ & $1.4^{\mathrm{a}} \pm 0.04$ & $1.1 \pm 0.03$ \\
\hline \multirow[t]{2}{*}{ Tyrosine } & Dorper & $2.5 \pm 0.21$ & $1.7 \pm 0.10$ & $32 \pm 0.11$ & $3.8^{\mathrm{a}} \pm 0.10$ & $2.8 \pm 0.08$ & $2.9 \pm 0.19$ & $2.4 \pm 0.17$ & $2.2^{\mathrm{b}} \pm 0.09$ & $2.0 \pm 0.12$ \\
\hline & Merino & $2.7 \pm 0.21$ & $1.9 \pm 0.10$ & $3.5 \pm 0.11$ & $3.4_{b} \pm 0.11$ & $2.8 \pm 0.10$ & $3.2 \pm 0.19$ & $2.4 \pm 0.17$ & $2.9^{\mathrm{a}} \pm 0.10$ & $2.1 \pm 0.12$ \\
\hline \multirow[t]{2}{*}{ Cysteine } & Dorper & $0.6 \pm 0.08$ & $0.4 \pm 0.04$ & $1.0^{\mathrm{b}} \pm 0.05$ & $1.2 \pm 0.05$ & $0.9 \pm 0.04$ & $0.7^{\mathrm{b}} \pm 0.06$ & $0.4 \pm 0.06$ & $0.7^{\mathrm{b}} \pm 0.04$ & $0.3 \pm 0.04$ \\
\hline & Merino & $0.7 \pm 0.08$ & $0.5 \pm 0.04$ & $1.2^{\mathrm{a}} \pm 0.05$ & $1.2 \pm 0.06$ & $1.0 \pm 0.05$ & $1.0^{\mathrm{a}} \pm 0.06$ & $0.5 \pm 0.06$ & $0.9^{\mathrm{a}} \pm 0.04$ & $0.3 \pm 0.04$ \\
\hline \multirow{2}{*}{ Isoleucine } & Dorper & $2.1 \pm 0.13$ & $1.8^{\mathrm{b}}+0.07$ & $2.6^{\mathrm{b}}+0.09$ & $3.2^{\mathrm{a}} \pm 0.08$ & $2.2 \pm 0.11$ & $22 \pm 0.13$ & $2.2 \pm 0.10$ & $2.1^{\mathrm{b}}+0.12$ & $1.9 \pm 0.09$ \\
\hline & Merino & $23 \pm 0.13$ & $2.1^{\mathrm{a}} \pm 0.08$ & $2.9^{\mathrm{a}} \pm 0.09$ & $2.8^{\mathrm{b}} \pm 0.09$ & $2.0 \pm 0.13$ & $2.5 \pm 0.13$ & $2.0 \pm 0.10$ & $2.6^{\mathrm{a}} \pm 0.13$ & $1.9 \pm 0.09$ \\
\hline \multirow[t]{2}{*}{ Phenylalanine } & Dorper & $28+0.22$ & $1.9 \pm 0.09$ & $3.1^{\mathrm{b}}+0.07$ & $4.1^{2}+0.10$ & $3.1^{\mathrm{b}}+0.07$ & $33+0.16$ & $2.4 \pm 0.12$ & $2.4^{\mathrm{b}}+0.07$ & $2.1+0.10$ \\
\hline & Merino & $3.0 \pm 0.22$ & $2.1 \pm 0.09$ & $3.5^{\mathrm{a}} \pm 0.07$ & $3.7^{b} \pm 0.11$ & $3.4^{\mathrm{a}} \pm 0.09$ & $3.4 \pm 0.16$ & $2.4 \pm 0.12$ & $2.9^{\mathrm{a}} \pm 0.08$ & $2.3 \pm 0.10$ \\
\hline \multirow[t]{2}{*}{ Leucine } & Dorper & $5.8 \pm 0.36$ & $4.7^{\mathrm{b}} \pm 0.17$ & $6.9^{\mathrm{b}} \pm 0.15$ & $8.2^{\mathrm{a}} \pm 0.15$ & $7.4^{\mathrm{b}} \pm 0.15$ & $7.3 \pm 0.31$ & $5.8 \pm 0.21$ & $5.6^{\mathrm{b}} \pm 0.16$ & $5.2 \pm 0.20$ \\
\hline & Merino & $62 \pm 0.36$ & $53^{\mathrm{a}} \pm 0.19$ & $7.7^{\mathrm{a}} \pm 0.15$ & $7.4^{\mathrm{b}} \pm 0.17$ & $82^{\mathrm{a}} \pm 0.19$ & $7.3 \pm 0.31$ & $5.8 \pm 0.21$ & $6.4^{\mathrm{a}} \pm 0.18$ & $5.2 \pm 0.20$ \\
\hline \multirow[t]{2}{*}{ Glycine } & Dorper & $2.7 \pm 0.15$ & $2.7 \pm 0.23$ & $2.6^{\mathrm{b}} \pm 0.25$ & $3.3 \pm 0.09$ & $4.7 \pm 0.14$ & $4.1 \pm 0.27$ & $6.1 \pm 0.34$ & $6.1 \pm 0.29$ & $4.2 \pm 0.30$ \\
\hline & Merino & $3.1 \pm 0.15$ & $2.8 \pm 0.25$ & $3.8^{\mathrm{a}} \pm 0.25$ & $3.2 \pm 0.09$ & $4.7 \pm 0.17$ & $4.4 \pm 0.27$ & $6.1 \pm 0.34$ & $5.3 \pm 0.32$ & $3.8 \pm 0.30$ \\
\hline \multirow[t]{2}{*}{ Hydroxyproline } & Dorper & $0.1^{\mathrm{b}} \pm 0.02$ & $0.4 \pm 0.07$ & $0.5^{\mathrm{b}} \pm 0.04$ & $0.2 \pm 0.03$ & $1.2 \pm 0.07$ & $0.7^{\mathrm{b}} \pm 0.09$ & $1.9 \pm 0.18$ & $2.0 \pm 0.18$ & $0.9 \pm 0.06$ \\
\hline & Merino & $0.2^{\mathrm{a}} \pm 0.02$ & $0.4 \pm 0.07$ & $0.8^{\mathrm{a}} \pm 0.04$ & $0.2 \pm 0.03$ & $1.1 \pm 0.09$ & $1.0^{\mathrm{a}} \pm 0.09$ & $2.0 \pm 0.18$ & $1.7 \pm 0.20$ & $0.9 \pm 0.06$ \\
\hline
\end{tabular}

$\mathrm{ab}$ means between breeds, within organs, with the same superscript do not differ $(P<0.05)$.

Arginine, histidine and methionine levels are similar to those reported by Schweigert et al. (1953) for dried lamb liver, kidney, heart, brain, pancreas, lung and spleen samples. The author, however, reported higher levels of threonine, valine, lysine, isoleucine, 
phenylalanine and leucine than were found in this study. The liver showed high levels of glutamic acid and leucine when compared to the other organs, the latter of which is in agreement with the findings of Schweigert et al. (1953). The stomach and the testicles both had high levels of arginine and glycine. The heart contained relatively low levels of alanine, aspartic acid, lysine, proline, phenylalanine and leucine when compared to the other organs. Schweigert, Guthneck, Kraybill, and Greenwood (1949) reported threonine, arginine, valine, lysine and isoleucine values of different fresh and cooked lamb cuts to be higher than the values found in any of the organs in the current study. The authors, however, reported similar histidine, methionine, phenylalanine and leucine values than were found in the organs. The organs were found to contain higher amounts of glutamic acid, aspartic acid and leucine, when compared to the other amino acids. The latter is, once again, in agreement with the findings of Schweigert et al. (1953).

\section{Conclusions}

From these findings, it is evident that although it is known that the nutritional composition of organs differs, there are also significant differences as a result of breed. Dorper organs tended to have a lower fat content than those of Merino. However, no differences were found for total saturated fatty acids (SFA) or total monounsaturated fatty acids (MUFA), whilst total polyunsaturated fatty acids (PUFA) differed between the two breeds with Dorper hearts having a significantly lower PUFA level than Merino hearts. Generally, the percentage of saturated fatty acids in the organs assessed were relatively high, and the meat cuts should be considered as high in saturated fats. However, all the organs with the exception of the tongue, heart and stomach, showed favourable P:S ratios. Both Dorper and Merino brain, lungs and testicles had favourable $n-6 / n-3$ ratios below five. Dorper heart and kidney had higher cholesterol contents than those of the Merino whilst Dorper liver had a lower cholesterol content than that of the Merino. In summary, the brain, kidney, liver, lung and spleen of both breeds should be considered high in cholesterol and therefore should be generally restricted in human diets.

\section{Acknowledgements}

The financial support of the South African Red Meat Research and Development Trust and the Food Security programme of the University of Stellenbosch is acknowledged. The help of the technical staff of the Department of Animal Sciences (Stellenbosch University) is appreciated. 


\section{References}

Abdullah, B. M. (2008). Composition, chemical and microbiological properties of Jordanian ovine organ meats. International Journal of Food Science and Technology, 43, $746-751$.

Aduku, A. O., Aganga, A. A., Okoh, P. N., Ingawa, S. A., \& Phillip, D. O. A. (1991). Contribution of offals to the gross value of goat carcasses in Nigeria. Small Ruminant Research, 6, 179-184.

AOAC (1997). Official methods of analysis (16th ed.). Arlington. Virginia. USA: Association of Official Analytical Chemists Inc..

AOAC (2003). Official methods of analysis Revision 2. (17th ed.). Arlington. Virginia. USA: Association of Official Analytical Chemists Inc..

Bagga, D., Wang, L., Farias-Eisner, R., Glaspy, J. A., \& Reddy, S. T. (2003). Differential ef- fects of prostaglandin derived from omega- 6 and omega-3 polyunsaturated fatty acids on COX-2 expression and IL-6 secretion. Proceedings of the National Academy of Sciences of the United States of America, 100, 1751-1756.

Das, U. N. (2006). Biological significance of essential fatty acids. The Journal of the Association of Physicians of India, 54, 309-319.

Department of Health (1994). Nutritional aspects of cardiovascular disease. Report on health and social subjects no. 46. London: H.M. Stationery Office.

Di Biase, A., \& Salvati, S. (1997). Exogenous lipids in myelination and myelination.

Kaohsiung Journal of Medical Sciences, 13(1), 19-29.

Fatma, H. M., \& Mahdey, E. A. (2010). Incidence of Brucella species in slaughtered food animals and its edible offal at Beni-suef, Egypt. Global Veterinaria, 5(5), 248-254.

Folch, J., Lees, M., \& Sloane Stanley, G. H. (1957). A simple method for the isolation and purification of total lipids from animal tissues. Journal of Biological Chemistry, 226, 497-509.

Grimm, H., Tibell, A., Norrlind, B., Blecher, C., Wilker, S., \& Schwemmle, K. (1994). Immunoregulation by parenteral lipids: Impact of the $n-3$ to $n-6$ fatty acid ratio. Journal of Parenteral and Enteral Nutrition, 18, 417-421.

Grundy, S. M. (1997). What is the desirable ratio of saturated, polyunsaturated and monounsaturated fatty acids in the diet? American Journal of Clinical Nutrition, 66, 988S-990S.

Hardman, W. E. (2002). Omega-3 fatty acids to augment cancer therapy. Journal of Nutrition, 132, 3508S-3512S.

Harris, W. S., Poston, W. C., \& Haddock, C. K. (2007). Tissue $n-3$ and n- 6 fatty acids and risk for coronary heart disease events. Atherosclerosis, 193, 1-10.

Hodson, L., Skeaff, C. M., \& Chisholm, W. -A. H. (2001). The effect of replacing dietary saturated fat with polyunsaturated or monounsaturated fat on plasma lipids in free living young adults. European Journal of Clinical Nutrition, 55, 908-915. 
Kamalzadeh, A., Koops, W. J., van Bruchem, J., Tamminga, S., \& Zwart, D. (1998). Feed quality restriction and compensatory growth in growing sheep: Development of body organs. Small Ruminant Research, 29, 71-82.

Kapoor, R., \& Huang, Y. S. (2006). Gamma linolenic acid: An antiinflammatory omega-6 fatty acid. Current Pharmaceutical Biotechnology, 7, 531-534.

Kiernat, H., Johnson, J. A., \& Siedler, A. J. (1964). A summary of the nutrient content of meat. American Meat Institute Foundation (Bulletin no. 47).

Lee, C. M., Trevino, B., \& Chaiyawat, M. (1996). A simple and rapid solvent extraction method for determining total lipids in fish tissue. Journal of AOAC International, 79(2), 487-492.

Lichtenstein, A. H., Appel, L. J., Brands, M., Carnethon, M., Daniels, S., Franch, H. A., Franklin, B., Kris-Etherton, P., Harris, W. S., Howard, B., Karanja, N., Lefevre, M., Rudel, L., Sacks, F., Van Horn, L., Winston, M., \& Wylie-Rosett, R. (2006). Diet and lifestyle recommendations revision 2006. A scientific statement from the American Heart Association Nutrition Committee. Circulation, 114, 82-96.

Liu, G., Bibus, D. M., Bode, A. M., Ma, W. -Y., Holman, R. T., \& Dong, Z. (2001). Omega 3 but not omega 6 fatty acids inhibit AP-1 activity and cell transformation in JB6 cells. Proceeding of the National Academy of Sciences (USA), 98, 7510-7515.

Milne, C. (2000). The history of the Dorper sheep. Small Ruminant Research, 36, 99102. Mustafa, F. A. (1988). Moisture, fat and cholesterol content of some raw; barbecued and cooked organ meats of beef and mutton. Journal of Food Science, 53, 270-271.

Ockerman, H. W., \& Basu, L. (2004). By-products. Encyclopaedia of Meat Science (pp. 104-112). : Elsevier.

Park, Y. W., Kouassi, M. A., \& Chin, K. B. (1991). Moisture, total fat and cholesterol in goat organ and muscle meat. Journal of Food Science, 56, 1191-1193.

Park, Y. W., \& Washington, A. C. (1993). Fatty acid composition of goat organ and muscle meat of Alpine and Nubian Breeds. Journal of Food Science, 58, 245-248 (253).

Pearson, A. M., \& Dutson, T. R. (1988). Edible meat by-products. In Advances in meat Research, 5. (pp. 197)England: Elsevier Science Publishers Ltd.

Raes, K., De Smet, S., \& Demeyer, D. (2004). Effect of dietary fatty acids on incorporation of long chain polyunsaturated fatty acids and conjugated linoleic acid in lamb, beef and pork meat: A review. Animal Science and Technology, 113, 199-221.

Sargent, J. R., Coupland, K., \& Wilson, R. (1994). Nervonic acid and demyelinating disease. Medical Hypotheses, 42, 237-242.

SAS Institute Inc. (2002-2005). SAS Online Documentation 9.1.3. Cary, NC: SAS Institute Inc. (http://www.sas.com/presscenter/guidelines.html)

Schweigert, B. S., Bennett, B. A., \& Guthneck, B. T. (1953). Amino acid composition of organ meats. American Meat Institute Foundation, 78, 219-223. 
Schweigert, B. S., Guthneck, B. T., Kraybill, H. R., \& Greenwood, D. A. (1949). The amino acid composition of pork and lamb cuts. Retrieved July 2, 2011 from the American Meat Institute Foundation (www.jbc.org)

Shrapnel, W. S., Calvert, G. D., Nestel, P. J., \& Truswell, A. S. (1992). Diet and cornonary heart disease. The nutritional heart foundation of Australia. Medical Journal of Australia, 4(156 Suppl.), S9-S16.

Siri-Tarino, P. W., Sun, Q., Hu, F. B., \& Krauss, R. M. (2010). Saturated fatty acids and risk of coronary heart disease: Modulation by replacement nutrients. Current Atherosclerosis Reports, 12, 384-390.

Sokolov, A. A., Pavlov, D. V., Bolshakov, A. S., Juravskayah, N. K., Kargaltsov, E. E., Yanushkin, N. P., et al. (1970). The technology of meat and meat products. Moscow, Russia: Pischevayah Promishlennost.

Terés, S., Barceló-Coblijn, G., Benet, M., Álvarez, R., Bressani, R., Halver, J. E., \& Escribá, P.V. (2008). Oleic acid content is responsible for the reduction in blood pressure induced by olive oil. Proceedings of the National Academy of Sciences (USA), 105, 1381113816.

U S Department of Agriculture, \& Agricultural Research Service (2011). USDA National Nutrient Database for Standard Reference, Release 24. Nutrient Data Laboratory Home Page (http://www.ars.usda.gov/nutrientdata. (accessed 22 March, 2012)).

Williams, P. G. (2007). Nutritional composition of red meat. Faculty of Health and behav- ioral Sciences paperFaculty of Health and Behavioral Science. Australia: University of Wollongong.

Wylie-Rosett, J. (2002). Fat substitutes and health - An advisory from the nutrition committee of the American Heart Association. Circulation, 105, 2800-2804.

Yehuda, S., Rabinovitz, S., \& Mostofsky, D. I. (1998). Modulation of learning and neurothe rat by essential fatty acid preparation: Time course analysis. Neurochemical Research, 23, 627-634. 